\title{
Gamma Delta T Cells and Their Pathogenic Role in Psoriasis
}

\author{
Cong $Q i^{1,2}$, Yazhuo Wang ${ }^{1,2}$, Ping $L i^{1,2}$ and Jingxia Zhao ${ }^{1,2 *}$ \\ ${ }^{1}$ Beijing Hospital of Traditional Chinese Medicine, Capital Medical University, Beijing, China, ${ }^{2}$ Beijing Key Laboratory of Clinic \\ and Basic Research with Traditional Chinese Medicine on Psoriasis, Beijing Institute of Traditional Chinese Medicine, Beijing, \\ China
}

$\gamma \delta T$ cells are an unconventional population of $T$ lymphocytes that play an indispensable role in host defense, immune surveillance, and homeostasis of the immune system. They display unique developmental, distributional, and functional patterns and rapidly respond to various insults and contribute to diverse diseases. Although $\gamma \delta \mathrm{T}$ cells make up only a small portion of the total $\mathrm{T}$ cell pool, emerging evidence suggest that aberrantly activated $\gamma \delta \mathrm{T}$ cells may play a role in the pathogenesis of psoriasis. Dermal $\gamma \delta \mathrm{T}$ cells are the major IL17-producing cells in the skin that respond to IL-23 stimulation. Furthermore, $\gamma \delta T$ cells exhibit memory-cell-like characteristics that mediate repeated episodes of psoriatic inflammation. This review discusses the differentiation, development, distribution, and biological function of $\gamma \delta T$ cells and the mechanisms by which they contribute to psoriasis.

OPEN ACCESS

Edited by:

Valerie Julia,

Galderma, Switzerland

Reviewed by:

Chuan Wu,

National Institutes of Health $(\mathrm{N} / \mathrm{H})$,

United States

Eva Reali,

University of Milano-Bicocca, Italy

*Correspondence:

Jingxia Zhao

zhaojingxia@bjzhongyi.com

Specialty section:

This article was submitted to

T Cell Biology,

a section of the journal

Frontiers in Immunology

Received: 08 November 2020

Accepted: 15 January 2021

Published: 25 February 2021

Citation:

Qi C, Wang Y, Li P and Zhao J (2021) Gamma Delta T Cells and Their

Pathogenic Role in Psoriasis.

Front. Immunol. 12:627139. doi: 10.3389/fimmu.2021.627139
Potential therapeutic approaches targeting these cells in psoriasis have also been detailed.

Keywords: psoriasis, $\gamma \delta \mathrm{T}$, IL-17, skin inflammation, biological function

\section{INTRODUCTION}

Gamma delta T cells ( $\gamma \delta \mathrm{T}$ cells) are T cells that have a distinctive T-cell receptor (TCR) on their surface. Most T cells are $\alpha \beta$ (alpha beta) T cells with TCR composed of two glycoprotein chains called $\alpha$ (alpha) and $\beta$ (beta) TCR chains. In contrast, gamma delta $(\gamma \delta)$ T cells have a TCR that is made up of one $\gamma$ (gamma) chain and one $\delta$ (delta) chain (1). This group of T cells is usually less common than $\alpha \beta$ T cells, but significantly enriched in mucosal and epithelial sites, such as the skin and respiratory, digestive, and reproductive tracts. $\gamma \delta \mathrm{T}$ cells are major histocompatibility complex (MHC)-unrestricted innate-like lymphocytes with more unique antigen receptors compared to $\alpha \beta T$ cells (2). They produce cytokines such as IL-17/IFN- $\gamma / \mathrm{IL}-22$ (3-5). Although they constitute a small portion of the total $\mathrm{T}$ cell pool, $\gamma \delta \mathrm{T}$ cells bridge the innate and adaptive immune system and contribute to various physiological and pathological processes (2). Relative to $\alpha \beta \mathrm{T}$ cells, $\gamma \delta \mathrm{T}$ cells have been less studied and characterized. It is becoming clear that $\gamma \delta \mathrm{T}$ cells are heterogeneous populations of cells with multifunctional capacities in repairing host tissue (6), pathogen clearance (7), tumor surveillance $(8,9)$, and proinflammatory effects $(10)$.

Psoriasis is a chronic inflammatory skin disease with an autoimmune component and a strong genetic basis. Plaque psoriasis is characterized by well-defined, raised, chronic erythematous plaques with silver patches observed commonly in the elbows, knees, scalp, umbilicus, and lumbar area (11-13). The worldwide reported prevalence of psoriasis ranges from $0.09 \%$ to $11.43 \%$ and results in a severe economic burden to patients and a significant challenge to public health $(14,15)$. Multiple comorbidities 
and other autoimmune disorders have been correlated with psoriasis, which includes arthritis, cardiovascular disease, obesity, diabetes mellitus, and inflammatory bowel disease, indicate common cellular mediators that drive the pathogenesis of these diseases (16). Increasing evidence has demonstrated that aberrantly activated $\gamma \delta \mathrm{T}$ cells may direct the pathogenesis of autoimmune disorders, such as psoriasis (17-19). To understand what they do in psoriasis, it is important to understand their the differentiation, development, distribution, and biological function.

In this review, we expound on the properties of $\gamma \delta \mathrm{T}$ cells and review the effects of $\gamma \delta \mathrm{T}$ cells in psoriasis. We hope that this review provides insights into its pathogenesis, especially in disease recurrence, and sheds light on potentially novel therapies targeting $\gamma \delta \mathrm{T}$ cell function.

\section{DIFFERENTIATION AND DEVELOPMENT OF $\gamma \delta$ T CELLS IN THE THYMUS}

$\gamma \delta \mathrm{T}$ cells were first discovered and reported 30 years ago during the manufacture of antibodies using the TCR $\gamma$ gene sequence (20). $\alpha \beta \mathrm{T}$ and $\gamma \delta \mathrm{T}$ cell lineages originate from common $\mathrm{T}$ precursor cells that lack CD4 and CD8 coreceptors (CD4CD8-), also known as double-negative (DN) thymocytes. Based on their differential CD44 and CD25 expression, DN cells can be further subdivided into DN1 (CD44+CD25-), DN2 (CD44+CD25+), DN3 (CD44-CD25+), and DN4 (CD44CD25-) stages, as indicated in Figure 1. Clonal assays for determining DNT cell progenitors permit the identification of the branch-point of $\alpha \beta \mathrm{T}$ and $\gamma \delta \mathrm{T}$ cell lineages at the late DN2 to DN3 developmental stages $(21,22)$. DN3 is the critical selection stage that determines the fate of $\gamma \delta$ or $\alpha \beta$ cell lineages (22). Rearrangements at the Tcrd, Tcrg, and Tcrb loci are initiated at the DN2 stage, and $\alpha \beta$ and $\gamma \delta$ lineage divergence occur at the DN3 stage $(23,24)$. Successful rearrangement of the TCR $\beta$ chain is achieved with the assembly of the constant $\mathrm{pT} \alpha$ and CD3 subunits to form the pre-TCR complex. Commitment to the $\alpha \beta T$ cell lineage and differentiation of DN3 cells into DN4 (CD44CD25-) cells transpires in a ligand-independent manner. This process is termed $\beta$-selection and is a checkpoint for the generation of a functional TCR $\beta$ chain $(25,26)$. TCR $\gamma$ and $\delta$ chains rearrange during the DN stages and express $\gamma \delta$ TCR/CD3 on the plasma membrane. ' $\gamma \delta$ selection' is associated with increased extracellular signal-related kinase 1/2(ERK1/2) phosphorylation and early growth response gene (Egr) protein expression. Ectopic expression of Egr proteins promotes the selection of the $\gamma \delta$ T cells. Inhibitor of DNA binding 3 (Id 3$)$ is an essential target by which Egr proteins regulate $\alpha \beta / \gamma \delta$ lineages (26-29).

What determines cell fate specification and differentiation from precursors to $\alpha \beta \mathrm{T}$ or $\gamma \delta \mathrm{T}$ lineage? Two models have been proposed, an instructive model and a stochastic model. In the instructive model, pre-TCR or $\gamma \delta$ TCR signaling intensities decide the fate of $\alpha \beta T / \gamma \delta \mathrm{T}$ cell lineage (30). The instructive model is based on several lines of evidence showing that the strong TCR signals are inclined to $\gamma \delta$ T cells, while the relatively weak TCR signals are inclined to generate abundant $\alpha \beta T$ lineage cells $(27,31,32)$. The stronger signals that promote adoption of the $\gamma \delta$-fate involve activation of the ERK-Egr-Id3 pathway $(29,33)$. Sang-Yun et al. demonstrated that ERK signaling promotes $\gamma \delta \mathrm{T}$ cell maturation. ERK signaling that promotes $\gamma \delta \mathrm{T}$ cell fate depends not only on conventional substrate targeting through the D-domain but also through an alternate mode of ERK action mediated by its DBP. This induces molecular effectors responsible for the execution of ERKmediated developmental outcomes post-transcriptionally (34). E proteins are helix-loop-helix transcription factors that bind DNA at E-box motifs (CANNTG). It acts as a downstream focal point for TCR and plays an essential role in thymocyte development (35). Strong TCR signals could selectively restrain $\alpha \beta T$ cell development by phenocopying E protein insufficiency and increasing ERK activation. This induces early growth response (EGR1, EGR3) transcription factors and targets DNA-binding inhibitors (ID3). ID3 has been shown to interact with and suppress E protein targets $(33,36,37)$.

Under stochastic conditions, other signals dominate this differentiation before TCR expression, hence pre-committing cell fate and allowing them to mature further. Increasing evidence has presented that progenitor $\mathrm{T}$ cells are heterogeneous in their developmental potential prior to TCR gene rearrangement. Their development potential has been associated with IL-7R expression (pre-T cells) and was independent of TCR-mediated signals (30). High mobility group box transcription factor 13 (Sox13) that modulate Wnt/ TCF1 signaling has also been reported to regulate the T cell-fate decision process, while Sox13 expression has been shown to promote $\gamma \delta \mathrm{T}$ cell development and restrain $\alpha \beta \mathrm{T}$ cell development $(38,39)$. Nevertheless, $\gamma \delta \mathrm{T}$ cell development has been observed in Sox13-deficient mice, suggesting that it is dispensable for $\gamma \delta \mathrm{T}$ cell development. This is contrary to what has been suggested in the stochastic model (38).

\section{DISTRIBUTION OF $\gamma \delta T$}

\section{Human $\gamma \delta T$ Cells}

Humans $\gamma \delta \mathrm{T}$ cells can be distinguished based on $\delta$ chain expression, which includes the $\mathrm{V} \delta 1, \mathrm{~V} \delta 2$, and $\mathrm{V} \delta 3$ subtypes (40) (Table 1). V $\delta 1$ cells are mainly found in the gut epithelium, skin, spleen, and liver, and are involved in maintaining epithelial tissue integrity. They constitute approximately $30 \%$ of the $\gamma \delta \mathrm{T}$ cells in the peripheral blood (PB). Typically, the $\mathrm{V} \delta 1$ chain is associated with different $\mathrm{V} \gamma \mathrm{I}$ family members ( $\mathrm{V} \gamma 2 / 3 / 4 / 5 / 8 / 9)$ (41-43). V $\delta 1$ cells exert their effector function through TCR recognition of stress molecules on epithelial cells. Furthermore, V $\delta 1$ cells express natural killer receptors (NKG2C, NKG2D, NKp30), Toll-like receptors, CD8, and the $\beta$-glucan receptor, dectin-1 (44-48). Activated V $\delta 1 \mathrm{~T}$ cells release IL-10, IL-2, IL-4, IL-17, IFN- $\gamma$, TNF- $\alpha$, and chemokines (CCL3, CCL4, and CCL5). V $\delta 1 \mathrm{~T}$ cells play an essential role in maintaining barrier tissue integrity and establishing antiviral immunity (49-51). Studies have demonstrated that $\mathrm{V} \delta 1$ cells are involved in 


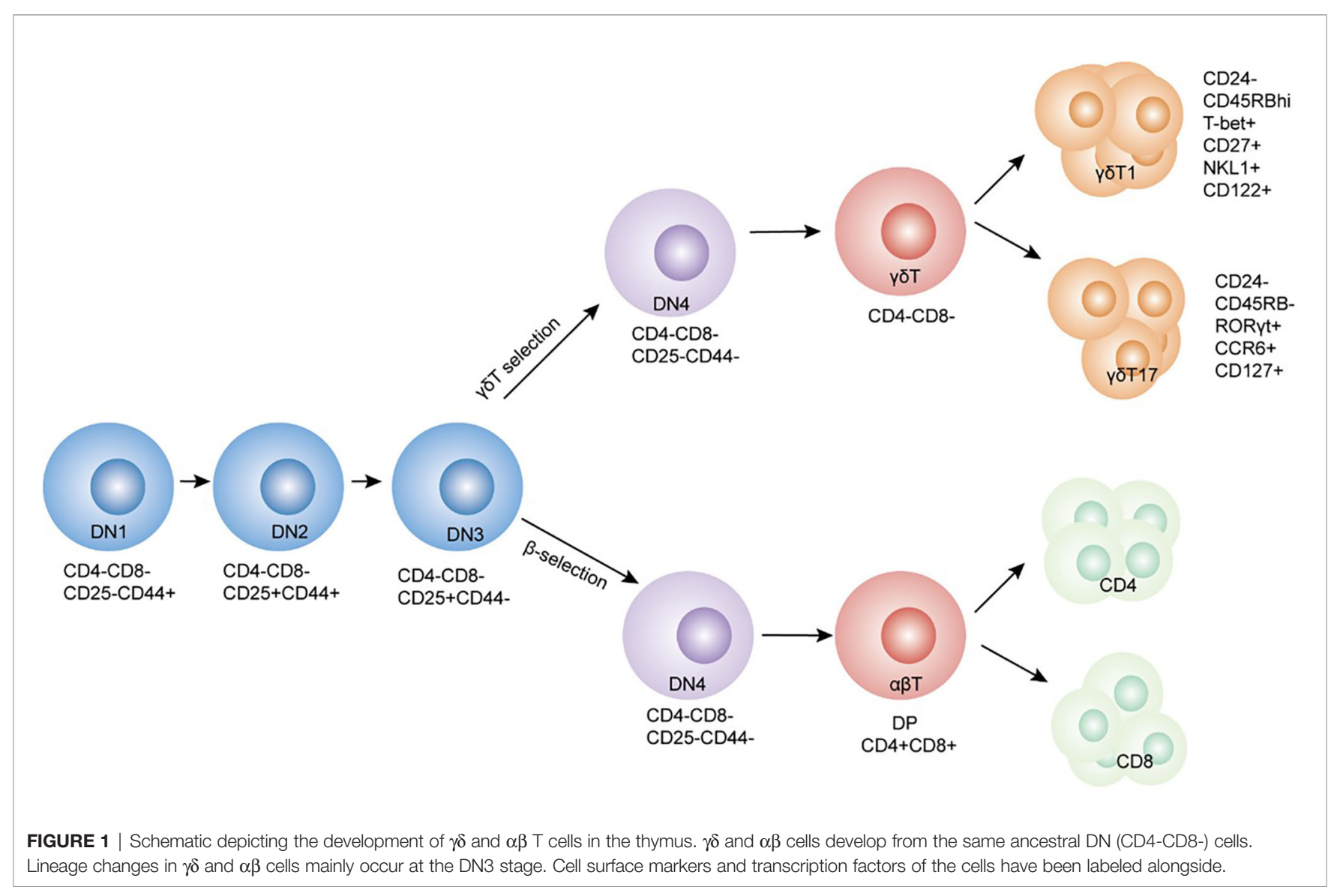

several diseases, such as malaria $(52,53)$, human immune deficiency virus (HIV) $(54,55)$, cytomegalovirus (CMV) (56), inflammatory bowel disease, and Crohn's disease by exerting their cytotoxic effects and secreting cytokines (57). Notably, activated V $\delta 1 \mathrm{~T}$ cells recognize $\mathrm{B} 7-\mathrm{H} 6$ via $\mathrm{NKp} 30$. B7-H6 is a B7 family member exclusively expressed on tumor cells and is involved in the antitumor effect (58).

$\mathrm{V} \delta 2 \mathrm{~T}$ cells are primarily distributed in the blood and the lymphoid system and are the main subset found in healthy humans. It accounts for $50 \%-90 \%$ of the $\gamma \delta \mathrm{T}$ cell population in peripheral blood (59). V $\delta 2 \mathrm{~T}$ cells are divided into the innate-like $\left(\mathrm{V} \gamma 9^{+}\right)$and adaptive $\left(\mathrm{V} \gamma 9^{-}\right)$subsets, with the majority of $\mathrm{V} \delta 2 \mathrm{~T}$ cells being $\mathrm{V} \delta 2 \mathrm{~V} \gamma 9+\mathrm{T}$ cells (60). $\mathrm{V} \delta 2 \mathrm{~V} \gamma 9+\mathrm{T}$ cells are responsive to cytokines, such as CCR1, CCR2, CCR5, and CXCR6 ligands and IL-12, and produce proinflammatory factors, such as IFN- $\gamma$, TNF- $\alpha$, IL-17, IL-21, and IL-24 $(61,62)$. V $\delta 2 \mathrm{~V} \gamma 9+\mathrm{T}$ cells can be divided into naive $\gamma \delta \mathrm{T}(\mathrm{CD} 45 \mathrm{RA}+\mathrm{CD} 27+\mathrm{V} \delta 2 \mathrm{~V} \gamma 9+)$, central memory $\gamma \delta \mathrm{T}$ (TCM, CD45RA-CD27+V $\delta 2 \mathrm{~V} \gamma$ ), effector memory $\gamma \delta \mathrm{T}$ (TEM, CD45RA-CD27-V $\delta 2 \mathrm{~V} \gamma 9+$ ), and CD45RA+ effector memory $\gamma \delta \mathrm{T}$ (TEMRA, CD45RA+CD27-V $\delta 2 \mathrm{~V} \gamma 9+$ ) based on their surface

TABLE 1 | Characteristics of human and murine $\gamma \delta$ T cell subsets.

\begin{tabular}{|c|c|c|c|c|}
\hline & Classify & Common pairs & Tissue resident & Production of cytokines \\
\hline & V $\delta 3$ & $\mathrm{~V} \gamma 2^{+} / 3^{+} / 4^{+}$ & PB, liver & IL-10,IL-4,IL-17,IFN- $\gamma$,TNF- $\alpha$ \\
\hline \multirow[t]{6}{*}{ Murine } & $V_{\gamma 1}$ & $V \gamma 6.3 / 6.4$ & skin, lung, colon, liver, PB & $\mathrm{IL}-4, \mathrm{IFN}-\gamma$ \\
\hline & Vү2 & V $\delta 4$ & skin, lung, colon, liver, PB & $\mathrm{IL}-17$ \\
\hline & $\vee \gamma \beta$ & V $\delta 1$ & skin & $?$ \\
\hline & $V_{\gamma 5}$ & $\vee \delta 1$ & skin, liver & $\mathrm{IL}-17, \mathrm{IFN}-\gamma$ \\
\hline & Vy6 & V $\delta 1$ & $\begin{array}{l}\text { genital tract, togue, lung, colon, skin, } \\
\text { adipose tissue }\end{array}$ & IL-17,IFN- $\gamma, \mathrm{IL}-22$ \\
\hline & $\vee \gamma 7$ & $V \delta 4 / 5 / 6$ & IEL (Intraepithelial lymphocytes) & $\mathrm{IFN}-\gamma$ \\
\hline
\end{tabular}

Heilig and Tonegawa nomenclature used for classification. 
expression of CD45RA and CD27. Naive $\gamma \delta \mathrm{T}$ cells comprise of the V $\delta 2 \mathrm{~V} \gamma 9+\mathrm{T}$ cell subset in the lymph nodes and express CCR7 and CD62L. However, CCR2, CCR5, CCR6, and CXCR3 are only expressed and activated in the presence of high concentrations of isopentenyl pyrophosphate (IPP) but do not produce IFN- $\gamma$. CM cells express CCR7 and CD62L and are activated at low IPP concentrations and produce some IFN- $\gamma$. TEM cells are present in the blood and inflammatory sites and are CCR7-CD62L-. However, they are positive for the chemokine receptors CCR2, CCR5, CCR6, and CXCR3. TEM cells secrete abundant IFN- $\gamma$ and tumor necrosis factor-alpha (TNF-a) when activated with IPP+IL-2. TEMRA cells are CCR7-CD62L- but express CCR5 and CXCR3, and have a cytotoxic effect. TEMRA cells also secrete abundant perforin, granulysin, and $\mathrm{N}$-a-benzyloxycarbonyl-L-lysine thiobenzyl ester (BLT)-esterase, but do not produce IFN- $\gamma$. In addition, they are terminally differentiated and are no longer able to respond to TCR stimulation, and have poor proliferative ability (63-66). V 22 specifically recognizes (E)-4-hydroxy-3-methyl-but-2-enyl pyrophosphate (HMB-PP) and isopentenyl pyrophosphate (IPP) and rapidly respond to exogenous infections or endogenous transformed cells $(67,68)$. Furthermore, activated $\mathrm{V} \delta 2 \mathrm{~V} \gamma 9+\mathrm{T}$ cells acquire antigen-presenting cell (APC) characteristics and display a strong ability to secrete cytokines, such as Th1/Th2/Th17-type cytokines. These induce the maturation of dendritic cells (DCs) into APCs (69-71).

$\mathrm{V} \delta 3 \mathrm{~T}$ cells are the smallest subsets of the peripheral blood lymphocytes, accounting for $0.2 \%$ of circulating cells. They express CD56, NKG2D, CD28, HLA-DR, CD161, and T cell activation marker CD69, but not CD25, NKG2A, or NKG2C (72). V83T cells are abundant in the liver and gut and are involved in chronic viral infections and leukemia $(73,74)$. Expanded V83T cells only recognize CD1d and release Th1, Th2, and Th17 cytokines to induce the maturation of dendritic cells into APCs. They do not recognize CD1a, CD1b, or CD1c (72). V $\delta 3 \mathrm{~T}$ cells and $\mathrm{B}$ cells reciprocally regulate the expression of maturation markers, CD40, CD86, and HLA-DR, and promote IgM release by B cells (75).

Interestingly, $\mathrm{V} \delta 4, \mathrm{~V} \delta 6, \mathrm{~V} \delta 7$, and $\mathrm{V} \delta 8 \mathrm{~T}$ cells have been observed in the $\mathrm{PB}$ of lymphoma patients, however, their roles are yet to be deciphered (76).

\section{Murine $\gamma \delta$ T Cells}

Murine $\gamma \delta \mathrm{T}$ cells can be distinguished based on their $\gamma$ chain expression. Two nomenclature methods have been commonly reported in the literature, i.e., the Heilig and Tonegawa, and the Garman classification $(77,78)$. This review uses the Heilig and Tonegawa nomenclature and is used for the $\mathrm{V} \gamma 1-\mathrm{V} \gamma 7$ subtypes (79) (Table 1).

The development of the $\gamma \delta \mathrm{T}$ subsets begins during the fetal period. First are the $\mathrm{V} \gamma 5+$ cells that are produced between embryonic day13 (E13) to approximately E17, followed by V $\gamma 6+$ cells from E14 to around birth, and the last are the $\mathrm{V} \gamma 1+, \mathrm{V} \gamma 2+$, and $V \gamma 4+$ cells from E16 onward $(25,80,81)$. V $\gamma 5+$ cells, also known as dendritic epidermal T cells (DETCs), are involved in innate body barrier defense. The increased expression of sphingosine-1-phosphate receptor 1 (S1P1), E and $\mathrm{P}$ selectin ligands, and chemokines CCR10 and CCR4 in mature V $\gamma 5+$ cells, and the decreased expression of CCR6, CCR9, CCR7, and CD62L allow the egression of $\mathrm{V} \gamma 5+$ cells from the thymus to the epidermis $(82,83)$. In normal healthy skin, DETC secretes IL-15 and IGF-1 to maintain skin homeostasis and promote wound healing $(84,85)$. After skin trauma, DETCs undergo morphological changes accompanied by the upregulation of the activation marker, CD69. It then releases soluble factors that regulate various aspects of tissue repair (85). DETCs produce CCL3 and CCL4 chemokines that are important for macrophage homing. Furthermore, DETCs promotes macrophage recruitment by regulating hyaluronan production through DETC-derived keratinocyte growth factor (KGF) $(86,87)$. V $\gamma 5+\mathrm{V} \delta 1+$ cells produce IFN- $\gamma$ by activating the Egr3-mediated pathway while suppressing the $\gamma \delta \mathrm{T}$ cell lineage factor, Sox13, and the ROR $\gamma \mathrm{t}$ transcription factor associated with IL-17 production (39). However, some studies have shown that DETCs produce IL-17, promote keratinocyte proliferation, and participate in skin inflammation (88).

The second $\gamma \delta \mathrm{T}$ subsets produced are the $\mathrm{V} \gamma 6$ cells. They pair with the $\mathrm{V} \delta 1$ subsets of $\gamma \delta \mathrm{TCR}(\mathrm{V} \gamma 6 \mathrm{~J} \gamma 1$ and $\mathrm{V} \delta 1 \mathrm{D} \delta 2 \mathrm{~J} \delta 2)$ and migrate to the genital tract, tongue, lungs, peritoneal cavity (PEC), dermis, colon, and adipose tissues (89). $\mathrm{V} \gamma 6+\mathrm{V} \delta 1+\gamma \delta \mathrm{T}$ cells that produce IL-17 and other effector molecules drive inflammation and tumor cell proliferation (90).

Typically, $\mathrm{V} \gamma 1+, \mathrm{V} \gamma 2+$, and $\mathrm{V} \gamma 4+$ cells migrate to the dermis, lungs, colon, liver, and peripheral lymphoid organs (91). Both $\mathrm{V} \gamma 1+$ and $\mathrm{V} \gamma 4+$ cells can secrete IFN- $\gamma$, TNF-a, TGF- $\beta$, and IL10 upon activation. However, $\mathrm{V} \gamma 1+\gamma \delta \mathrm{T}$ cells are predisposed to produced IL-4 and IL-5, while $\mathrm{V} \gamma 4+\gamma \delta \mathrm{T}$ cells preferentially produce IL-17 (92). $V \gamma 1+\gamma \delta$ T cells occur mainly in the form of V $\gamma 1 \mathrm{~V} \delta 6.3 / 6.4$ TCR cells and secrete IL-4 and IFN- $\gamma$ (93). Upon acute infection with Coxsackievirus B3 (CVB3), $V \gamma 1+\gamma \delta \mathrm{T}$ cells are the early and primary producers of IL-4 and play a protective role in CVB3 myocarditis (94). V $\gamma 4+\gamma \delta \mathrm{T}$ cells express high levels of Rorc, Sox13, Scart, Bclaf1, and Atf2 and secrete abundant levels of IL-17A and IL-17F (92) (95). IL-17A-producing $\mathrm{V} \gamma 4+\gamma \delta \mathrm{T}$ cells also express high levels of CCR6 on their surface and are chemoattracted by CCL20 that are secreted by keratinocytes to inflammatory sites, which in turn facilitates keratinocytes to secrete IL-1 $\beta$ and IL-23 (96). In addition, IL-17 secreted by $\mathrm{V} \gamma 4+\gamma \delta \mathrm{T}$ cells inhibits the production of IGF-1, thereby delaying skin wound healing $(84,97)$. Studies have shown that $\mathrm{V} \gamma 2+\mathrm{T}$ cells recruit neutrophils and aggravate liver fibrosis by secreting IL-17A $(98,99)$. It has also been demonstrated that $\mathrm{V} \gamma 7+\mathrm{T}$ cells are the main components of the murine intestinal intraepithelial $\mathrm{T}$ cell compartment. Consequently, the selective maturation and expansion of $\mathrm{V} \gamma 7+\mathrm{T}$ cells are driven by both Btnl1 and Btnl6 (100).

\section{BIOLOGICAL EFFECTS OF $\gamma \delta T$ CELLS}

$\gamma \delta \mathrm{T}$ cells have strong plasticity and secrete different cytokines and chemokines. They exhibit diverse functions similar to Th1, Th2, Tregs, and Th17 cells in different microenvironments (2). 
Some $\gamma \delta$ T cells generate growth factors such as VEGF, FGF-2, and IGF-1, suggesting that these cells have the capacity to maintain epithelial integrity and wound repair (101). Nonetheless, some $\gamma \delta \mathrm{T}$ cells have been reported to induce the production of antimicrobial peptides, including $\beta$-defensin 2 , S100A7, and S100A8 in keratinocytes to exert a protective function in local epithelial defense (101). $\gamma \delta \mathrm{T}$ cells secrete interleukin-10 (IL-10), control CD8 $+\mathrm{T}$ cell expansion, and regulate and reduce TNF-a secretion by activated CD8+ T cells (102). The role of IL-17-producing $\gamma \delta \mathrm{T}$ cells has been investigated in various models of infection and autoimmunity (103, 104). IL-17-producing $\gamma \delta \mathrm{T}$ cells robustly direct the recruitment of neutrophils and monocytes to increase the inflammatory response.

$\gamma \delta \mathrm{T}$ cells are involved in the regulation of macrophage homeostasis and recruitment. In patients suffering from listeriosis (a serious infection caused by the germ Listeria monocytogenes), $\gamma \delta \mathrm{T}$ cells play a critical role in neutrophil replacement by producing chemokines such as macrophage chemoattractant protein1 (MCP-1) (105). Additional evidence has shown that $\gamma \delta \mathrm{T}$ cells facilitate differentiation of the monocyte/macrophage lineage. Remarkably, monocytes differentiate into inflammatory macrophages during bacterial infections but fail to undergo maturation in mice lacking $\gamma \delta \mathrm{T}$ cells (106). In contrast, the role of V $\gamma 4$ has been demonstrated to enhance macrophage activity and the production of specific proinflammatory and immunoregulatory cytokines by macrophages. Different subsets of $\gamma \delta \mathrm{T}$ cells have opposing roles in macrophage homeostasis, indicating the complexity and plasticity of $\gamma \delta \mathrm{T}$ cells (107). $\gamma \delta \mathrm{T}$ cells present antigens to $\alpha \beta \mathrm{T}$ cells, while $\mathrm{V} \delta 2+\mathrm{T}$ cells display characteristics similar to professional APCs. Once activated, these cells efficiently process and present antigens and prime co-stimulatory signals for potent induction of $\alpha \beta \mathrm{T}$ cell proliferation and differentiation (108). Receptors associated with DC, such as antigen presentation molecules (MHC class II), co-stimulatory receptors (CD40, CD80, and CD86), maturation markers (CD83), and adhesion receptors (CD11a, CD11b, CD11c, CD18, CD50, and CD54) have been found to be expressed on the surface of activated $\gamma \delta \mathrm{T}$ cells $(109,110)$.

Activated $\gamma \delta \mathrm{T}$ cells exhibit a broad range of cytotoxic activity, especially against a wide variety of tumor cells that utilize death receptor/ligand (Fas/Fas-ligand)-dependent and perforin/granzyme or granulysin-dependent pathways. Exogenous IL-18 promotes the expansion of $\gamma \delta \mathrm{T}$ cells in human peripheral blood mononuclear cells (PBMCs) stimulated by Zoledronate (Zol) and IL-2 (109). The expansion of $\gamma \delta \mathrm{T}$ cells is inhibited by neutralizing anti-IL-18 receptor antibodies, indicating that IL-18 efficiently promotes the expansion of $\gamma \delta \mathrm{T}$ cells with potent antitumor activity (110). Furthermore, studies have shown that $\gamma \delta \mathrm{T}$ cells directly kill activated hepatic stellate cells (HSCs) and increase NK cellmediated cytotoxicity against activated HSCs in liver fibrosis (10).

$\gamma \delta \mathrm{T}$ cells are highly efficient in promoting $\mathrm{B}$ cell maturation and producing IgM, IgG, and IgA antibodies. V $\delta 2 \mathrm{~V} \gamma 9 \mathrm{~T}$ cells express IL-21R on their surface, which is enhanced upon HMB$\mathrm{PP}$ induced irritation $(111,112)$. Activated $\mathrm{V} \delta 2 \mathrm{~V} \gamma 9 \mathrm{~T}$ cells express CXCL13, CXCR5, and ICOS and upregulate the expression of B cell surface markers CD25, CD69, CD40, and CD86. This suggests that CXCR5+ V $\delta 2 \mathrm{~V} \gamma 9 \mathrm{~T}$ cells are a distinct memory $\mathrm{T}$ cell subset with $\mathrm{B}$ cell helper function $(111,113)$.

\section{$\gamma \delta T$ IN PSORIASIS}

Dysregulation of the immune system and $\mathrm{T}$ cell activation has been well demonstrated to play an essential role in psoriasis development. Several studies have attributed $\mathrm{T}$ cell function in the skin to $\alpha \beta T$ cells, while $\gamma \delta$ T cells have been often overlooked. IFN- $\gamma$-producing $\mathrm{T}$ helper (Th) 1 cells were initially thought to be primary drivers of psoriasis. However, substantial clinical and basic research findings in the past decade have proved that the interleukin (IL)-23/Th17 axis plays an important role in the pathogenesis of psoriasis $(114,115)$. Psoriatic inflammation was found to be impaired in IL-23- and IL-17-deficient mice, thereby confirming the involvement of the IL-23/IL-17 axis $(116,117)$. Th17 cells and their downstream effector molecules, including IL-17A, IL-17F, IL-22, and tumor necrosis factor (TNF- $\alpha$ ), were found to be increased in the sera and psoriatic skin lesion (118). Recently, Th17 cells were found not to be the primary source of these pathogenic cytokines in psoriasis. Instead, IL-17A, IL-17F, and IL-22 were found to be produced by $\gamma \delta$ T cells (115). Injecting IL-23 into the skin of mice or applying a topical dose of imiquimod cream (5\%) induced a typical psoriasis-like phenotype, i.e., epidermal thickness, erythema, and inflammation. These two models were demonstrated to mimic psoriasis-like inflammation and have been used to evaluate the efficacy of different treatment methods (119). Epidermal hyperplasia and inflammation response induced by IL-23/IMQ was observed to be significantly reduced in T cell receptor $\delta$ deficient $\left(\mathrm{Tcrd}^{-/-}\right)$mice, however, no significant changes were observed in $\mathrm{T}$ cell receptor $\beta$ deficient $\mathrm{Tcrb}^{-/-}$mice (120). In addition, Cai et al. demonstrated that upon IL-23 stimulation, IL-17 produced in $\mathrm{Tcrd}^{-/-}$mice was significantly lower compared to WT or $\mathrm{Tcra}^{-1-}$ mice (121). These data further suggested that dermal $\gamma \delta \mathrm{T}$ cells were the major IL-17-producing cells in the skin in response to IL-23 stimulation.

The production of IL-17 by dermal $\gamma \delta \mathrm{T}$ cells requires endogenous IL-1 $\beta$ (121). Mechanistically, IL-1 $\beta$ activates the mammalian target of rapamycin (mTOR) signaling pathway via IL-1R-MyD88, whereas IL-23 activates the STAT3 pathway. Transcription factor IRF-4 links the IL-1R and IL-23R pathways to induce enhanced IL-17 production in dermal $\gamma \delta \mathrm{T}$ cells (122). Both V $\gamma 4$ and $\mathrm{V} \gamma 6$ dermal T cells produce IL-17, however, dermal $\mathrm{V} \gamma 4 \mathrm{~T}$ cells expand and produce significantly more IL-17 compared to V $\gamma 6$ (123). Dermal V $\gamma 4$ and V $\gamma 6 \mathrm{~T}$ cells have different effector signaling requirements. Dermal V $\gamma 4 \mathrm{~T}$ cell proliferation and IL-17 production are dependent on STAT3, whereas dermal V $66 \mathrm{~T}$ cells may be activated through the STAT3-independent RelA/NF-kB pathway (122). Thus, dermal V $\gamma 4 \mathrm{~T}$ cells appear to have a critical role in IMQ-induced psoriasis-like dermatitis (123).

Dermal $\gamma \delta$ T cells constitutively express IL-23R, IL-17R, ROR $\gamma t$, and the chemokine receptors CCR1, CCR2, CCR4, CCR5, CCR6, 
CXCR3, and CXCR4 $(120,121)$. CCL20, which is a unique CCR6 ligand, mediates skin infiltration of IL-17-producing $\gamma \delta \mathrm{T}$-cells and DCs. Numerous studies have shown that CCL20/CCR6 regulates T migration from the dermis to the epidermis, promotes neutrophil aggregation, and exacerbates inflammation (124). In IL-23-injected WT mice, CCL20 was highly upregulated with numerous CCR6+ $\gamma \delta \mathrm{T}$ cells observed in the epidermis (125). Anti-CCL20-neutralizing antibodies or engineered CCL20 variants with minimal chemotactic activity prevented the infiltration of IL-17-producing $\gamma \delta$ T-cell into the skin of IL-23-injected mice. This lead to IL-17 and IL-22 downregulation, blocked $\gamma \delta \mathrm{T}$ cell recruitment to the epidermis, and reduced psoriasiform dermatitis $(126,127)$. In CCR6-knockout (KO) mice, $\gamma \delta \mathrm{T}$ cells failed to migrate and accumulate in the epidermis after IL-23 treatment. Keratinocytes secrete CCL20, bind and activate CCR6, and regulate the migration of $\gamma \delta \mathrm{T}$ cell subsets into the skin. This suggests the potential relevance of CCR6/CCL20 as a therapeutic target for psoriasis $(126,128,129)$.

Psoriasis recurs frequently and relapse occurs in the same area after treatment discontinuation. Hence, recurrent psoriasis is a major problem that needs to be solved. TNF-a, IL-12/23, and IL17 inhibitors have been shown to exhibit potent and rapid therapeutic efficacy $(130,131)$. However, these biological agents have been associated with several adverse events, the most common being susceptibility to infections (130). In addition to infections, biological inhibitors have been associated with demyelinating diseases, nasopharyngitis, upper respiratory infection, headaches, lupus, or lupus-like syndromes, mucocutaneous candidiasis, mild neutropenia, and new-onset or worsening of heart failure. The longterm safety concerns and high cost hamper the extensive use of these agents $(130,132,133)$.

Psoriasis relapses around the original lesion area suggest these manifestations have an "immune memory." Adaptive immune responses by memory $\mathrm{T}$ cells are not limited to foreign antigens, and relapses in autoimmune diseases are typically driven by autoaggressive memory lymphocytes. There have been published reports regarding the adaptive-type memory responses in $\gamma \delta \mathrm{T}$ cells. The response of human $\mathrm{V} \gamma \rho \mathrm{V} \delta 2+\mathrm{T}$ cells to phospho-antigens is increased after initial Mycobacterium bovis BCG vaccinations (134). In macaques, a memory-type response and rapid expansion of $\mathrm{V} \gamma 9 \mathrm{~V} \delta 2 \mathrm{~T}$ cells have been observed after a secondary challenge with Bacillus Calmette-Guerin (135). Mouse "memory-like" V $\gamma 6+$ $\gamma \delta \mathrm{T}$ cells were found to be retained for more than five months in the mesenteric lymph nodes after Listeria monocytogenes infection (136).

Memory-like $\gamma \delta \mathrm{T}$ has been seen in psoriasiform mouse model, IL-17A-producing V $\gamma 2 \mathrm{~V} \delta 4+\mathrm{T}$ cells initially derive from the neonatal thymus where they are instructed with tissue tropism. These V $\gamma 2 \mathrm{~V} \delta 4+\mathrm{T}$ cells were phenotypically memory-like with a CD44hi CD62Llo CD27- expression pattern (137). After exposure to IMQ, $V \gamma 4+\gamma \delta \mathrm{T} 17$ cells in the skin have been shown to rapidly expand in the draining lymph nodes (LNs) and then release from the LNs. They then migrate via the action of the chemokine, CCR2, to accumulate at sites of both inflamed and uninflamed skin in a S1P1-dependent manner. This in turn exacerbates the inflammatory response and recruitment of neutrophils. They have also been shown to migrate via the blood and persist in normal skin and peripheral LNs for a minimum of three months. Importantly, when subjected to the same second challenge at a distant skin site, memory-like $\mathrm{V} \gamma 4+\gamma \delta \mathrm{T} 17$ cells expand at a faster rate and produce more IL-17 compared to that after exposure to the first challenge, leading to a rapid and severe skin inflammatory response (19) (Figure 2). Sensitized mice showed elevated skin inflammation, significant cell proliferation, and IL-17 production by $\mathrm{V} \gamma 4+\gamma \delta \mathrm{T}$ cells upon IMQ challenge. Adoptive transfer experiments have confirmed that memory-like $V \gamma 4+\gamma \delta \mathrm{T} 17$ cells respond rapidly, and their memory drives their involvement in the psoriasis recurrence $(19,138,139)$.

$\gamma \delta \mathrm{T}$ cells are rarely found in healthy human skin (140), however, they are easily generated from the skin of psoriatic patients. $\gamma \delta \mathrm{T}$ cells have different adhesion properties compared to $\alpha \beta T$ cell subsets (141). A higher frequency of sequence sharing of the $\gamma$-chain has been found in psoriatic lesions from different individuals compared to those without psoriasis, suggesting that although the $\mathrm{T}$ cell response in psoriasis is highly polyclonal, particular $\gamma \delta \mathrm{T}$ cell subsets could be associated with this disease (142). Following study demonstrated that an increased level of $\mathrm{V} \gamma \rho \mathrm{V} \delta 2 \mathrm{~T}$ cells was present in psoriatic skin compared to healthy controls, while a significant reduction in $\mathrm{V} \gamma \mathrm{V} \delta 2$ cells was observed in the blood of psoriasis patients. The number of circulating $\mathrm{V} \gamma 9 \mathrm{~V} \delta 2 \mathrm{~T}$ cells returned to normal levels after successful psoriasis-targeted treatment. These findings demonstrated the redistribution of V $\gamma 9 \mathrm{~V} \delta 2 \mathrm{~T}$ cells from the blood to the skin of psoriasis patients (101). The recruitment of specific monoclonal population of $\gamma \delta \mathrm{T}$ cells to psoriatic skin suggests local expression or modification of a cognate TCR ligand that is recognized by this population of memory-like $\gamma \delta$ T cells (143). Consistently, Zheng group found the higher expression of $\mathrm{V} \gamma \rho$ in psoriasis lesion than that in healthy individuals, indicating that $\mathrm{V} \gamma \rho \gamma \delta \mathrm{T}$ cells may be the main pathogenic cell (144). Additionally, $\mathrm{V} \gamma 9 \mathrm{~V} \delta 2 \mathrm{~T}$ cells have been shown to produce psoriasis-relevant cytokines, such as IFN- $\gamma$, TNF- $\alpha$, and IL-17A and chemokines such as IL-8, CCL3, CCL4, CCL5, and CCR6. These cytokines and chemokines are responsible for recruiting crucial immune effector cells to the skin to activate keratinocytes $(63,145)$.

\section{TARGETING $\gamma \delta$ T CELLS FOR PSORIASIS THERAPY}

The important role of dermal immobilized $\gamma \delta \mathrm{T}$ cells in the pathogenesis of psoriasis has been elucidated in the past years. Hence, dermal $\gamma \delta \mathrm{T}$ cells and their associated molecules have become attractive targets for drug development. Adiponectin, a metabolic mediator of insulin sensitivity, plays a crucial role in metabolic regulation and inflammatory/anti-inflammatory processes. Studies have demonstrated that in psoriasiform skin, inflammation, and infiltration of dermal $\gamma \delta \mathrm{T}$ cells producing IL17 were significantly enhanced in the absence of adiponectin. The negative regulation of adiponectin on IL-17 production from dermal $\gamma \delta \mathrm{T}$ cells is mainly mediated through AdipoR1. This 


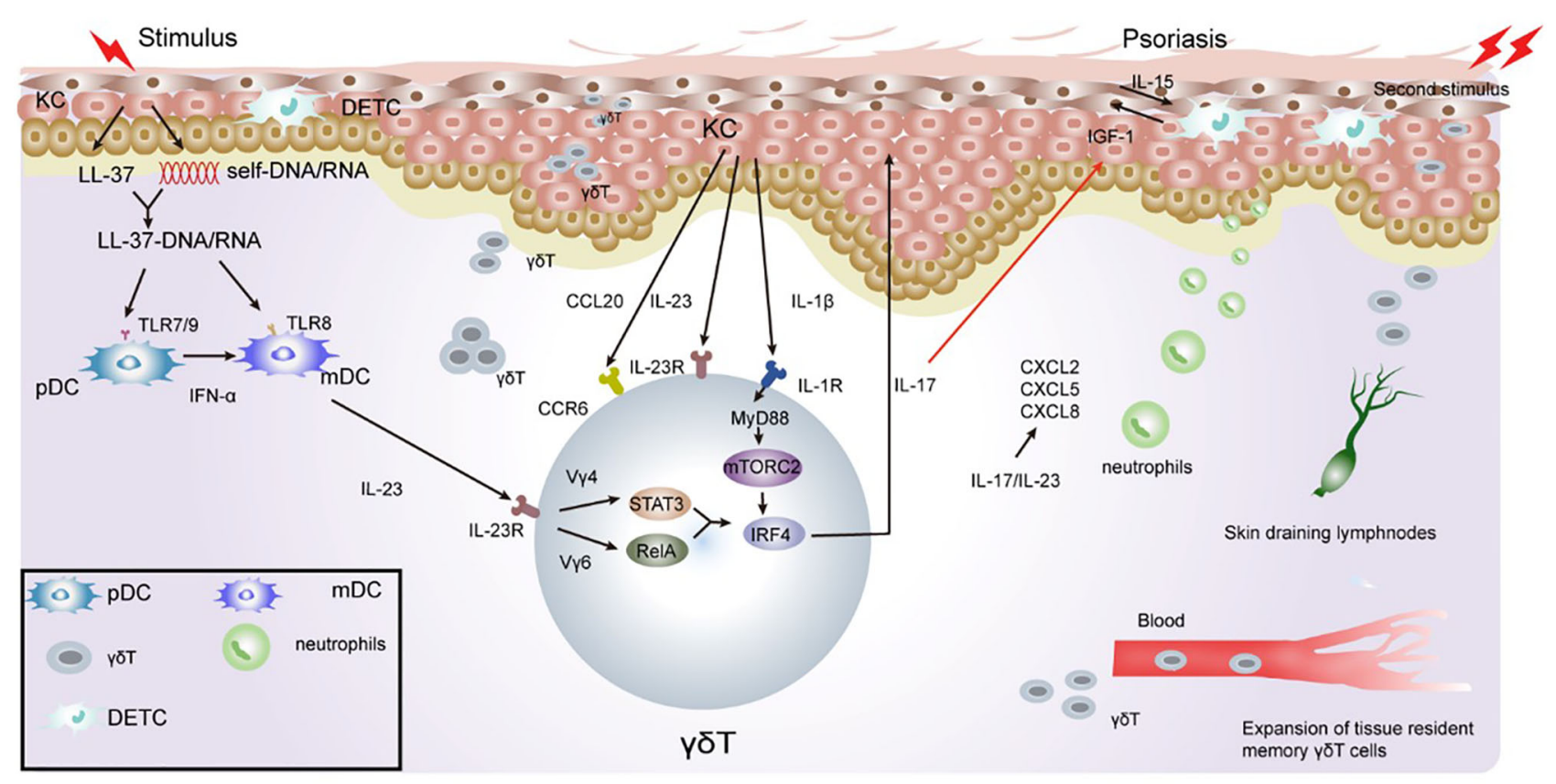

FIGURE 2 | Role of $\gamma \delta$ T cells in the immune pathogenesis of psoriasis. Keratinocytes in the epidermis undergo apoptosis, necrosis, or death when exposed to certain external stimulation. With the release of cell contents, such as DNA and RNA, keratinocytes release antimicrobial peptides, such as LL-37. LL-37 binds with DNA and RNA to form a complex, promote immature DC activation, and secrete IFN- $\gamma /$ IL-23 through the TLR7/8/9 pathway. IL-23 activates ROR $\gamma t+\gamma \delta T$ cells to secrete IL-17. $\gamma \delta$ T cell-derived IL-17 directly inhibits IGF-1 production in DETCs by increasing epidermal IL-23/IL-1 $\beta$ expression. During excessive keratinocyte proliferation, the secretion of TNF- $\alpha$ and chemokine ligand 20 (CCL20) increases, which consequently recruits CCR6+ $\gamma \delta T$ cells to the inflammatory site of the epidermis. IL-17 cytokines produced by $\gamma \delta$ T cells potently upregulate the chemokine, CCL20, in keratinocytes, which chemoattracts IL-17A-producing CCR6+ immune cells to the inflamed site, thus forming a positive feedback loop. II-23/L-17 also promotes the recruitment of neutrophils to inflammatory sites, leading to excessive proliferation of the stratum corneum to form psoriatic inflammatory lesions. $\gamma \delta T$ cells have memory properties and can migrate rapidly to inflammatory sites through the blood and skin when subjected to a secondary stimulation. This consequently gives rise to severe inflammatory manifestations.

suggests that increasing adiponectin levels may be effective for improving psoriasis as well as metabolic disorders $(146,147)$. BTLA belongs to the immunoglobulin superfamily and has been reported to play a role in the homeostasis of $\gamma \delta \mathrm{T}$ cells/ILCs in lymphoid tissues and controls the production of IL-17 in mature lymph node $\gamma \delta$ T cells. BTLA-deficient animal models have been shown to have a dysregulated proportion of inflammatory $\gamma \delta \mathrm{T}$ cells and were susceptible to psoriasis and severe skin inflammation. BTLA agonism was found to limit the progression of these phenotypes. Activation of BTLA may restore the balance of $\gamma \delta \mathrm{T}$ cell subsets to control autoimmune pathogenesis $(148,149)$. The agonistic anti-BTLA antibody (clone 6A6) was demonstrated to suppress $\gamma \delta \mathrm{T}$ cell expansion and IL-17 production within the lymph nodes and skin induced by IMQ $(149,150)$. Thus, BTLA may be a potential target for the treatment of psoriasis. Dermal $\gamma \delta \mathrm{T}$ cells constitutively express CCR6. CCR6KO or anti-CCL20 monoclonal antibodies administered to mice resulted in a decline in psoriatic dermatitis in IL-23-induced skin inflammation mouse models. This demonstrates that CCL20, together with its receptor, CCR6, are potential targets for the treatment of psoriasis $(129,151)$. CCL20 S64C is a CCL20 variant that binds to CCR6 and inhibits
CCR6-mediated T cell migration. Previous studies have shown that CCL20 S64C alleviates the inflammatory response in psoriasis-like models induced by IL-23, and have been associated with reduced accumulation of CCR6+ IL-17producing $\gamma \delta \mathrm{T}$ cells in the epidermis (127). FTY720 is an FDA-approved immunomodulatory drug for the treatment of multiple sclerosis. It reduces lymphocyte egress from lymphoid tissues by inhibiting the sphingosine-1 phosphate receptor (S1PR). FTY720 inhibits the migration of $\mathrm{V} \gamma 4+\mathrm{V} \gamma \mathrm{T} 4+\mathrm{T} 17$ cells from the lymph nodes to the skin, suggesting its potential as a treatment for psoriasis (152). Indirubin (IR) is a bisindole compound extracted from the leaves of the Chinese herb Indigo naturalis. It has been demonstrated to alleviate IMQ-induced psoriasis-like dermatitis by primarily reducing the inflammatory responses mediated by IL-17 A-producing $\gamma \delta \mathrm{T}$ cells through Jak3/Stat3 activation (153). Dashlkhumbe et al. reported a newly formulated methotrexate (MTX, a chemical conjugate of MTX with a cell-permeable peptide) for the treatment of psoriasis. Topically applied skin-penetrating (SP)-MTX reduced the psoriasiform skin phenomenon and epidermal thickness by reducing $\mathrm{CD} 11 \mathrm{c}+, \mathrm{CD} 4+$, and $\mathrm{IL}-17$-producing $\gamma \delta \mathrm{T}$ cellcontaining infiltrate of immune cells in the skin (154). 


\section{CONCLUSIONS AND FUTURE DIRECTIONS}

Psoriasis has a complex and varied pathogenesis. During disease development, $\gamma \delta \mathrm{T}$ cells secrete proinflammatory cytokines, such as IL-17 and IFN- $\gamma$, which induce and aggravate psoriasis. Notably, $\gamma \delta \mathrm{T}$ cells have memory cell properties that rapidly respond to secondary stimulation. This contributes to the recurrence of psoriasis.

Future studies should investigate whether $\gamma \delta \mathrm{T}$ cells that reside in skin lesions have resident memory cell properties, how long they persist, how often they turn over, and what environmental niches within peripheral tissues support their long-term survival. Studies have shown that metabolism and immune function are tightly linked $(155,156)$. Nutrient availability and cellular metabolism tightly control the differentiation, survival, and function of immune cells (157). However, whether cellular metabolism regulates $\gamma \delta \mathrm{T}$ fate decisions remains to be deciphered. Additional studies are necessary to identify the

\section{REFERENCES}

1. Holtmeier W, Kabelitz D. gammadelta T cells link innate and adaptive immune responses. Chem Immunol Allergy (2005) 86:151-83. doi: 10.1159/000086659

2. Lu H, Li DJ, Jin LP. gammadeltaT Cells and Related Diseases. Am J Reprod Immunol (2016) 75:609-18. doi: 10.1111/aji.12495

3. Ness-Schwickerath KJ, Morita CT. Regulation and function of IL-17A- and IL-22-producing gammadelta T cells. Cell Mol Life Sci (2011) 68:2371-90. doi: 10.1007/s00018-011-0700-z

4. Reinhardt A, Prinz I. Whodunit? The Contribution of Interleukin (IL)-17/ IL-22-Producing gammadelta T Cells, alphabeta T Cells, and Innate Lymphoid Cells to the Pathogenesis of Spondyloarthritis. Front Immunol (2018) 9:885. doi: 10.3389/fimmu.2018.00885

5. Raverdeau M, Cunningham SP, Harmon C, Lynch L. gammadelta T cells in cancer: a small population of lymphocytes with big implications. Clin Transl Immunol (2019) 8:e01080. doi: 10.1002/cti2.1080

6. Xu P, Fu X, Xiao N, Guo Y, Pei Q, Peng Y, et al. Involvements of gammadeltaT Lymphocytes in Acute and Chronic Skin Wound Repair. Inflammation (2017) 40:1416-27. doi: 10.1007/s10753-017-0585-6

7. Zhang S, Kan X, Li Y, Li P, Zhang C, Li G, et al. Deficiency of gammadeltaT cells protects against abdominal aortic aneurysms by regulating phosphoinositide 3-kinase/AKT signaling. J Vasc Surg (2018) 67:899908.e1. doi: 10.1016/j.jvs.2016.03.474

8. Girard P, Charles J, Cluzel C, Degeorges E, Manches O, Plumas J, et al. The features of circulating and tumor-infiltrating gammadelta $\mathrm{T}$ cells in melanoma patients display critical perturbations with prognostic impact on clinical outcome. Oncoimmunology (2019) 8:1601483. doi: 10.1080/ 2162402X.2019.1601483

9. Kierkels GJJ, Scheper W, Meringa AD, Johanna I, Beringer DX, Janssen A, et al. Identification of a tumor-specific allo-HLA-restricted gammadeltaTCR. Blood Adv (2019) 3:2870-82. doi: 10.1182/bloodadvances.2019032409

10. Liu M, Hu Y, Yuan Y, Tian Z, Zhang C. gammadeltaT Cells Suppress Liver Fibrosis via Strong Cytolysis and Enhanced NK Cell-Mediated Cytotoxicity Against Hepatic Stellate Cells. Front Immunol (2019) 10:477. doi: 10.3389/ fimmu.2019.00477

11. Schadler ED, Ortel B, Mehlis SL. Biologics for the primary care physician: Review and treatment of psoriasis. Dis Mon (2019) 65:51-90. doi: 10.1016/ j.disamonth.2018.06.001

12. Arnone M, Takahashi MDF, Carvalho AVE, Bernardo WM, Bressan AL, Ramos AMC, et al. Diagnostic and therapeutic guidelines for plaque psoriasis - Brazilian Society of Dermatology. Bras Dermatol (2019) 94:76107. doi: 10.1590/abd1806-4841.2019940211 mechanisms that reduce $\gamma \delta \mathrm{T}$ cells to prevent the recurrence of psoriasis.

\section{AUTHOR CONTRIBUTIONS}

CQ drafted and edited the manuscript. CQ drafted and edited the figures and figure legends. YW and PL edited the manuscript. JZ edited and approved the final version of the manuscript. All authors contributed to the article and approved the submitted version.

\section{FUNDING}

This work was supported by the National Natural Science Foundation of China (No. 81673989 and No. 82074434) and the Beijing municipal health system high-level health technology talent team construction project (No. 2015-3-116).

13. Lee $\mathrm{EB}, \mathrm{Wu} \mathrm{KK}$, Lee $\mathrm{MP}$, Bhutani $\mathrm{T}, \mathrm{Wu}$ JJ. Psoriasis risk factors and triggers. Cutis (2018) 102:18-20.

14. Michalek IM, Loring B, John SM. A systematic review of worldwide epidemiology of psoriasis. J Eur Acad Dermatol Venereol (2017) 31:20512. doi: $10.1111 /$ jdv.13854

15. Boehncke WH, Schon MP. Psoriasis. Lancet (2015) 386:983-94. doi 10.1016/S0140-6736(14)61909-7

16. Hawkes JE, Chan TC, Krueger JG. Psoriasis pathogenesis and the development of novel targeted immune therapies. J Allergy Clin Immunol (2017) 140:645-53. doi: 10.1016/j.jaci.2017.07.004

17. Mo WX, Yin SS, Chen H, Zhang X. Amino-bisphosphonates, gammadeltaT cells, and their roles in Rheumatoid Arthritis. Ann Rheum Dis (2018) 77:e58. doi: 10.1136/annrheumdis-2017-212569

18. Ma H, Yuan Y, Zhao L, Ye Z, Xu J, Li M, et al. Association of gammadelta T Cell Compartment Size to Disease Activity and Response to Therapy in SLE. PLoS One (2016) 11:e0157772. doi: 10.1371/journal.pone.0157772

19. Ramirez-Valle F, Gray EE, Cyster JG. Inflammation induces dermal Vgamma4+ gammadeltaT17 memory-like cells that travel to distant skin and accelerate secondary IL-17-driven responses. Proc Natl Acad Sci U S A (2015) 112:8046-51. doi: 10.1073/pnas.1508990112

20. Brenner MB, McLean J, Dialynas DP, Strominger JL, Smith JA, Owen FL, et al. Identification of a putative second T-cell receptor. Nature (1986) 322:145-9. doi: 10.1038/322145a0

21. Zhang X, Dong X, Wang H, Li J, Yang B, Zhang J, et al. FADD regulates thymocyte development at the beta-selection checkpoint by modulating Notch signaling. Cell Death Dis (2014) 5:e1273. doi: 10.1038/cddis.2014.198

22. Michie AM, Zuniga-Pflucker JC. Regulation of thymocyte differentiation: pre-TCR signals and beta-selection. Semin Immunol (2002) 14:311-23. doi: 10.1016/S1044-5323(02)00064-7

23. Fahl SP, Coffey F, Wiest DL. Origins of gammadelta T cell effector subsets: a riddle wrapped in an enigma. J Immunol (2014) 193:4289-94. doi: 10.4049/ jimmunol.1401813

24. Livak F, Tourigny M, Schatz DG, Petrie HT. Characterization of TCR gene rearrangements during adult murine T cell development. J Immunol (1999) 162:2575-80.

25. Muro R, Takayanagi H, Nitta T. T cell receptor signaling for gammadeltaT cell development. Inflammation Regener (2019) 39:6. doi: 10.1186/s41232019-0095-Z

26. Chann AS, Russell SM. An integrated transcriptional switch at the betaselection checkpoint determines $\mathrm{T}$ cell survival, development and leukaemogenesis. Biochem Soc Trans (2019) 47:1077-89. doi: 10.1042/ BST20180414 
27. Haks MC, Lefebvre JM, Lauritsen JP, Carleton M, Rhodes M, Miyazaki T, et al. Attenuation of gammadeltaTCR signaling efficiently diverts thymocytes to the alphabeta lineage. Immunity (2005) 22:595-606. doi: 10.1016/j.immuni.2005.04.003

28. Taghon T, Yui MA, Pant R, Diamond RA, Rothenberg EV. Developmental and molecular characterization of emerging beta- and gammadelta-selected pre- $\mathrm{T}$ cells in the adult mouse thymus. Immunity (2006) 24:53-64. doi: 10.1016/j.immuni.2005.11.012

29. Carpenter AC, Bosselut R. Decision checkpoints in the thymus. Nat Immunol (2010) 11:666-73. doi: 10.1038/ni.1887

30. Kang J, Volkmann A, Raulet DH. Evidence that gammadelta versus alphabeta $\mathrm{T}$ cell fate determination is initiated independently of $\mathrm{T}$ cell receptor signaling. J Exp Med (2001) 193:689-98. doi: 10.1084/jem.193.6.689

31. Kreslavsky T, Garbe AI, Krueger A, von Boehmer H. T cell receptor-instructed alphabeta versus gammadelta lineage commitment revealed by single-cell analysis. J Exp Med (2008) 205:1173-86. doi: 10.1084/jem.20072425

32. Zarin P, Wong GW, Mohtashami M, Wiest DL, Zuniga-Pflucker JC. Enforcement of gammadelta-lineage commitment by the pre-T-cell receptor in precursors with weak gammadelta-TCR signals. Proc Natl Acad Sci U S A (2014) 111:5658-63. doi: 10.1073/pnas.1312872111

33. Lauritsen JP, Wong GW, Lee SY, Lefebvre JM, Ciofani M, Rhodes M, et al. Marked induction of the helix-loop-helix protein Id3 promotes the gammadelta $\mathrm{T}$ cell fate and renders their functional maturation Notch independent. Immunity (2009) 31:565-75. doi: 10.1016/j.immuni.2009.07.010

34. Lee SY, Coffey F, Fahl SP, Peri S, Rhodes M, Cai KQ, et al. Noncanonical mode of ERK action controls alternative alphabeta and gammadelta $\mathrm{T}$ cell lineage fates. Immunity (2014) 41:934-46. doi: 10.1016/j.immuni.2014.10.021

35. Engel I, Murre C. The function of E- and Id proteins in lymphocyte development. Nat Rev Immunol (2001) 1:193-9. doi: 10.1038/35105060

36. Ciofani M, Zuniga-Pflucker JC. Determining gammadelta versus alphass $\mathrm{T}$ cell development. Nat Rev Immunol (2010) 10:657-63. doi: 10.1038/nri2820

37. Zarin P, Chen EL, In TS, Anderson MK, Zuniga-Pflucker JC. Gamma delta T-cell differentiation and effector function programming, TCR signal strength, when and how much? Cell Immunol (2015) 296:70-5. doi: 10.1016/j.cellimm.2015.03.007

38. Melichar HJ, Narayan K, Der SD, Hiraoka Y, Gardiol N, Jeannet G, et al. Regulation of gammadelta versus alphabeta $\mathrm{T}$ lymphocyte differentiation by the transcription factor SOX13. Science (2007) 315:230-3. doi: 10.1126/ science. 1135344

39. Turchinovich G, Hayday AC. Skint-1 identifies a common molecular mechanism for the development of interferon-gamma-secreting versus interleukin-17-secreting gammadelta T cells. Immunity (2011) 35:59-68. doi: 10.1016/j.immuni.2011.04.018

40. Fichtner AS, Ravens S, Prinz I. Human gammadelta TCR Repertoires in Health and Disease. Cells (2020) 9:800. doi: 10.3390/cells9040800

41. Bonneville M, O’Brien RL, Born WK. Gammadelta T cell effector functions: a blend of innate programming and acquired plasticity. Nat Rev Immunol (2010) 10:467-78. doi: 10.1038/nri2781

42. Wesch D, Hinz T, Kabelitz D. Analysis of the TCR Vgamma repertoire in healthy donors and HIV-1-infected individuals. Int Immunol (1998) 10:1067-75. doi: 10.1093/intimm/10.8.1067

43. Davey MS, Willcox CR, Joyce SP, Ladell K, Kasatskaya SA, McLaren JE, et al. Clonal selection in the human Vdeltal $\mathrm{T}$ cell repertoire indicates gammadelta TCR-dependent adaptive immune surveillance. Nat Commun (2017) 8:14760. doi: 10.1038/ncomms 14760

44. Maher CO, Dunne K, Comerford R, O’Dea S, Loy A, Woo J, et al. Candida albicans stimulates IL-23 release by human dendritic cells and downstream IL-17 secretion by Vdelta1 T cells. J Immunol (2015) 194:5953-60. doi: 10.4049/jimmunol.1403066

45. Fausther-Bovendo H, Wauquier N, Cherfils-Vicini J, Cremer I, Debre P, Vieillard V. NKG2C is a major triggering receptor involved in the V[delta] 1 T cell-mediated cytotoxicity against HIV-infected CD4 T cells. AIDS (2008) 22:217-26. doi: 10.1097/QAD.0b013e3282f46e7c

46. Wesch D, Peters C, Oberg HH, Pietschmann K, Kabelitz D. Modulation of gammadelta T cell responses by TLR ligands. Cell Mol Life Sci (2011) 68:2357-70. doi: 10.1007/s00018-011-0699-1

47. Hudspeth K, Fogli M, Correia DV, Mikulak J, Roberto A, Della Bella S, et al. Engagement of NKp30 on Vdeltal T cells induces the production of
CCL3, CCL4, and CCL5 and suppresses HIV-1 replication. Blood (2012) 119:4013-6. doi: 10.1182/blood-2011-11-390153

48. Kuroda H, Saito H, Ikeguchi M. Decreased number and reduced NKG2D expression of Vdeltal gammadelta $\mathrm{T}$ cells are involved in the impaired function of Vdeltal gammadelta $\mathrm{T}$ cells in the tissue of gastric cancer. Gastric Cancer (2012) 15:433-9. doi: 10.1007/s10120-011-0138-x

49. Mao Y, Yin S, Zhang J, Hu Y, Huang B, Cui L, et al. A new effect of IL-4 on human gammadelta $\mathrm{T}$ cells: promoting regulatory Vdelta1 $\mathrm{T}$ cells via IL-10 production and inhibiting function of Vdelta2 T cells. Cell Mol Immunol (2016) 13:217-28. doi: 10.1038/cmi.2015.07

50. Chabab G, Barjon C, Abdellaoui N, Salvador-Prince L, Dejou C, Michaud $\mathrm{HA}$, et al. Identification of a regulatory Vdeltal gamma delta $\mathrm{T}$ cell subpopulation expressing CD73 in human breast cancer. J Leukoc Biol (2020) 107:1057-67. doi: 10.1002/JLB.3MA0420-278RR

51. Singh AK, Novakova L, Axelsson M, Malmestrom C, Zetterberg H, Lycke J, et al. High Interferon-gamma Uniquely in Vdeltal T Cells Correlates with Markers of Inflammation and Axonal Damage in Early Multiple Sclerosis. Front Immunol (2017) 8:260. doi: 10.3389/fimmu.2017.00260

52. Hviid L, Smith-Togobo C, Willcox BE. Human Vdelta1(+) T Cells in the Immune Response to Plasmodium falciparum Infection. Front Immunol (2019) 10:259. doi: 10.3389/fimmu.2019.00259

53. Rutishauser T, Lepore M, Di Blasi D, Dangy JP, Abdulla S, Jongo S, et al. Activation of TCR Vdelta1(+) and Vdelta1(-)Vdelta2(-) gammadelta T Cells upon Controlled Infection with Plasmodium falciparum in Tanzanian Volunteers. J Immunol (2020) 204:180-91. doi: 10.4049/jimmunol.1900669

54. Dunne PJ, Maher CO, Freeley M, Dunne K, Petrasca A, Orikiiriza J, et al. CD3epsilon Expression Defines Functionally Distinct Subsets of Vdelta1 T Cells in Patients With Human Immunodeficiency Virus Infection. Front Immunol (2018) 9:940. doi: 10.3389/fimmu.2018.00940

55. Pauza CD, Poonia B, Li H, Cairo C, Chaudhry S. gammadelta T Cells in HIV Disease: Past, Present, and Future. Front Immunol (2014) 5:687. doi: 10.3389/fimmu.2014.00687

56. Knight A, Arnouk H, Britt W, Gillespie GY, Cloud GA, Harkins L, et al. CMV-independent lysis of glioblastoma by ex vivo expanded/activated Vdelta1+ gammadelta T cells. PLoS One (2013) 8:e68729. doi: 10.1371/ journal.pone. 0068729

57. Lo Presti E, Di Mitri R, Mocciaro F, Di Stefano AB, Scibetta N, Unti E, et al. Characterization of gammadelta T Cells in Intestinal Mucosa From Patients With Early-Onset or Long-Standing Inflammatory Bowel Disease and Their Correlation With Clinical Status. J Crohns Colitis (2019) 13:873-83. doi: 10.1093/ecco-jcc/jjz015

58. Correia DV, Fogli M, Hudspeth K, da Silva MG, Mavilio D, Silva-Santos B. Differentiation of human peripheral blood Vdeltal+ T cells expressing the natural cytotoxicity receptor NKp30 for recognition of lymphoid leukemia cells. Blood (2011) 118:992-1001. doi: 10.1182/blood-2011-02-339135

59. Dimova T, Brouwer M, Gosselin F, Tassignon J, Leo O, Donner C, et al. Effector Vgamma9Vdelta2 $\mathrm{T}$ cells dominate the human fetal gammadelta Tcell repertoire. Proc Natl Acad Sci U S A (2015) 112:E556-65. doi: 10.1073/ pnas. 1412058112

60. Davey MS, Willcox CR, Hunter S, Kasatskaya SA, Remmerswaal EBM, Salim $\mathrm{M}$, et al. The human Vdelta2(+) T-cell compartment comprises distinct innate-like Vgamma9(+) and adaptive Vgamma9(-) subsets. Nat Commun (2018) 9:1760. doi: 10.1038/s41467-018-04076-0

61. Kress E, Hedges JF, Jutila MA. Distinct gene expression in human Vdeltal and Vdelta2 gammadelta $\mathrm{T}$ cells following non-TCR agonist stimulation. Mol Immunol (2006) 43:2002-11. doi: 10.1016/j.molimm.2005.11.011

62. Moens E, Brouwer M, Dimova T, Goldman M, Willems F, Vermijlen D. IL23R and TCR signaling drives the generation of neonatal Vgamma9Vdelta2 $\mathrm{T}$ cells expressing high levels of cytotoxic mediators and producing IFNgamma and IL-17. J Leukoc Biol (2011) 89:743-52. doi: 10.1189/jlb.0910501

63. Pang DJ, Neves JF, Sumaria N, Pennington DJ. Understanding the complexity of gammadelta T-cell subsets in mouse and human. Immunology (2012) 136:283-90. doi: 10.1111/j.1365-2567.2012.03582.x

64. Caccamo N, Meraviglia S, Ferlazzo V, Angelini D, Borsellino G, Poccia F, et al. Differential requirements for antigen or homeostatic cytokines for proliferation and differentiation of human Vgamma9Vdelta2 naive, memory and effector T cell subsets. Eur J Immunol (2005) 35:1764-72. doi: 10.1002/ eji.200525983 
65. Dieli F, Poccia F, Lipp M, Sireci G, Caccamo N, Di Sano C, et al. Differentiation of effector/memory Vdelta2 $\mathrm{T}$ cells and migratory routes in lymph nodes or inflammatory sites. J Exp Med (2003) 198:391-7. doi: 10.1084/jem.20030235

66. De Rosa SC, Andrus JP, Perfetto SP, Mantovani JJ, Herzenberg LA, Herzenberg LA, et al. Ontogeny of gamma delta T cells in humans. J Immunol (2004) 172:1637-45. doi: 10.4049/jimmunol.172.3.1637

67. Hintz M, Reichenberg A, Altincicek B, Bahr U, Gschwind RM, Kollas AK, et al. Identification of (E)-4-hydroxy-3-methyl-but-2-enyl pyrophosphate as a major activator for human gammadelta T cells in Escherichia coli. FEBS Lett (2001) 509:317-22. doi: 10.1016/S0014-5793(01)03191-X

68. Wang H, Sarikonda G, Puan KJ, Tanaka Y, Feng J, Giner JL, et al. Indirect stimulation of human Vgamma2Vdelta2 $\mathrm{T}$ cells through alterations in isoprenoid metabolism. J Immunol (2011) 187:5099-113. doi: 10.4049/ jimmunol.1002697

69. Dunne MR, Mangan BA, Madrigal-Estebas L, Doherty DG. Preferential Th1 cytokine profile of phosphoantigen-stimulated human Vgamma9Vdelta2 T cells. Mediators Inflamm (2010) 2010:704941. doi: 10.1155/2010/704941

70. Petrasca A, Doherty DG. Human Vdelta2(+) gammadelta T Cells Differentially Induce Maturation, Cytokine Production, and Alloreactive T Cell Stimulation by Dendritic Cells and B Cells. Front Immunol (2014) 5:650. doi: 10.3389/fimmu.2014.00650

71. Devilder MC, Maillet S, Bouyge-Moreau I, Donnadieu E, Bonneville M, Scotet E. Potentiation of antigen-stimulated V gamma 9V delta $2 \mathrm{~T}$ cell cytokine production by immature dendritic cells (DC) and reciprocal effect on DC maturation. J Immunol (2006) 176:1386-93. doi: 10.4049/ jimmunol.176.3.1386

72. Mangan BA, Dunne MR, O'Reilly VP, Dunne PJ, Exley MA, O'Shea D, et al. Cutting edge: CD1d restriction and Th1/Th2/Th17 cytokine secretion by human Vdelta3 T cells. J Immunol (2013) 191:30-4. doi: 10.4049/ jimmunol.1300121

73. Kenna T, Golden-Mason L, Norris S, Hegarty JE, O'Farrelly C, Doherty DG. Distinct subpopulations of gamma delta $\mathrm{T}$ cells are present in normal and tumor-bearing human liver. Clin Immunol (2004) 113:56-63. doi: 10.1016/ j.clim.2004.05.003

74. Dunne MR, Elliott L, Hussey S, Mahmud N, Kelly J, Doherty DG, et al. Persistent changes in circulating and intestinal gammadelta $\mathrm{T}$ cell subsets, invariant natural killer $\mathrm{T}$ cells and mucosal-associated invariant $\mathrm{T}$ cells in children and adults with coeliac disease. PLoS One (2013) 8:e76008. doi: 10.1371/journal.pone.0076008

75. Petrasca A, Melo AM, Breen EP, Doherty DG. Human Vdelta3(+) gammadelta $\mathrm{T}$ cells induce maturation and IgM secretion by B cells. Immunol Lett (2018) 196:126-34. doi: 10.1016/j.imlet.2018.02.002

76. Wang L, Xu M, Wang C, Zhu L, Hu J, Chen S, et al. The feature of distribution and clonality of TCR gamma/delta subfamilies T cells in patients with B-cell non-Hodgkin lymphoma. J Immunol Res (2014) 2014:241246. doi: 10.1155/2014/241246

77. Heilig JS, Tonegawa S. Diversity of murine gamma genes and expression in fetal and adult T lymphocytes. Nature (1986) 322:836-40. doi: 10.1038/ $322836 \mathrm{a} 0$

78. Garman RD, Doherty PJ, Raulet DH. Diversity, rearrangement, and expression of murine T cell gamma genes. Cell (1986) 45:733-42. doi: 10.1016/0092-8674(86)90787-7

79. Munoz-Ruiz M, Sumaria N, Pennington DJ, Silva-Santos B. Thymic Determinants of gammadelta $\mathrm{T}$ Cell Differentiation. Trends Immunol (2017) 38:336-44. doi: 10.1016/j.it.2017.01.007

80. Prinz I, Silva-Santos B, Pennington DJ. Functional development of gammadelta T cells. Eur J Immunol (2013) 43:1988-94. doi: 10.1002/ eji.201343759

81. Carding SR, Egan PJ. Gammadelta T cells: functional plasticity and heterogeneity. Nat Rev Immunol (2002) 2:336-45. doi: 10.1038/nri797

82. Jiang X, Campbell JJ, Kupper TS. Embryonic trafficking of gammadelta T cells to skin is dependent on E/P selectin ligands and CCR4. Proc Natl Acad Sci U S A (2010) 107:7443-8. doi: 10.1073/pnas.0912943107

83. Nakamura K, White AJ, Parnell SM, Lane PJ, Jenkinson EJ, Jenkinson WE, et al. Differential requirement for CCR4 in the maintenance but not establishment of the invariant Vgamma5(+) dendritic epidermal T-cell pool. PLoS One (2013) 8:e74019. doi: 10.1371/journal.pone.0074019
84. Li Y, Wu J, Luo G, He W. Functions of Vgamma4 T Cells and Dendritic Epidermal T Cells on Skin Wound Healing. Front Immunol (2018) 9:1099. doi: 10.3389/fimmu.2018.01099

85. Havran WL, Jameson JM. Epidermal T cells and wound healing. J Immunol (2010) 184:5423-8. doi: 10.4049/jimmunol.0902733

86. Jameson JM, Cauvi G, Sharp LL, Witherden DA, Havran WL. Gammadelta $\mathrm{T}$ cell-induced hyaluronan production by epithelial cells regulates inflammation. J Exp Med (2005) 201:1269-79. doi: 10.1084/jem.20042057

87. Ramirez K, Witherden DA, Havran WL. All hands on DE(T)C: Epithelialresident gammadelta T cells respond to tissue injury. Cell Immunol (2015) 296:57-61. doi: 10.1016/j.cellimm.2015.04.003

88. Nielsen MM, Lovato P, MacLeod AS, Witherden DA, Skov L, DyringAndersen B, et al. IL-1beta-dependent activation of dendritic epidermal T cells in contact hypersensitivity. I Immunol (2014) 192:2975-83. doi: 10.4049/jimmunol.1301689

89. Hatano S, Tun X, Noguchi N, Yue D, Yamada H, Sun X, et al. Development of a new monoclonal antibody specific to mouse Vgamma6 chain. Life Sci Alliance (2019) 2. doi: 10.26508/lsa.201900363

90. Jin C, Lagoudas GK, Zhao C, Bullman S, Bhutkar A, Hu B, et al. Commensal Microbiota Promote Lung Cancer Development via gammadelta T Cells. Cell (2019) 176:998-1013.e16. doi: 10.1016/j.cell.2018.12.040

91. Buus TB, Schmidt JD, Bonefeld CM, Geisler C, Lauritsen JP. Development of interleukin-17-producing Vgamma2+ gammadelta $\mathrm{T}$ cells is reduced by ICOS signaling in the thymus. Oncotarget (2016) 7:19341-54. doi: 10.18632/ oncotarget.8464

92. Dong P, Zhang S, Cai M, Kang N, Hu Y, Cui L, et al. Global characterization of differential gene expression profiles in mouse Vgammal+ and Vgamma4+ gammadelta T cells. PLoS One (2014) 9:e112964. doi: 10.1371/journal.pone.0112964

93. Pereira P, Berthault C, Burlen-Defranoux O, Boucontet L. Critical role of TCR specificity in the development of Vgamma1Vdelta6.3+ innate NKTgammadelta cells. J Immunol (2013) 191:1716-23. doi: 10.4049/jimmunol.1203168

94. Wan F, Yan K, Xu D, Qian Q, Liu H, Li M, et al. Vgammal(+)gammadeltaT, early cardiac infiltrated innate population dominantly producing IL-4, protect mice against CVB3 myocarditis by modulating IFNgamma(+) T response. $\mathrm{Mol}$ Immunol (2017) 81:16-25. doi: 10.1016/j.molimm.2016.11.006

95. Papotto PH, Ribot JC, Silva-Santos B. IL-17(+) gammadelta T cells as kickstarters of inflammation. Nat Immunol (2017) 18:604-11. doi: 10.1038/ ni. 3726

96. Li Y, Huang Z, Yan R, Liu M, Bai Y, Liang G, et al. Vgamma4 gammadelta T Cells Provide an Early Source of IL-17A and Accelerate Skin Graft Rejection. J Invest Dermatol (2017) 137:2513-22. doi: 10.1016/j.jid.2017.03.043

97. Li Y, Wang Y, Zhou L, Liu M, Liang G, Yan R, et al. Vgamma4 T Cells Inhibit the Pro-healing Functions of Dendritic Epidermal T Cells to Delay Skin Wound Closure Through IL-17A. Front Immunol (2018) 9:240. doi: 10.3389/fimmu.2018.00240

98. Spidale NA, Sylvia K, Narayan K, Miu B, Frascoli M, Melichar HJ, et al. Interleukin-17-Producing gammadelta $\mathrm{T}$ Cells Originate from SOX13(+) Progenitors that Are Independent of gammadeltaTCR Signaling. Immunity (2018) 49:857-72.e5. doi: 10.1016/j.immuni.2018.09.010

99. Zheng L, Hu Y, Wang Y, Huang X, Xu Y, Shen Y, et al. Recruitment of Neutrophils Mediated by Vgamma2 gammadelta T Cells Deteriorates Liver Fibrosis Induced by Schistosoma japonicum Infection in C57BL/6 Mice. Infect Immun (2017) 85. doi: 10.1128/IAI.01020-16

100. Di Marco Barros R, Roberts NA, Dart RJ, Vantourout P, Jandke A, Nussbaumer O, et al. Epithelia Use Butyrophilin-like Molecules to Shape Organ-Specific gammadelta T Cell Compartments. Cell (2016) 167:20318.e17. doi: 10.1016/j.cell.2016.08.030

101. Laggner U, Di Meglio P, Perera GK, Hundhausen C, Lacy KE, Ali N, et al. Identification of a novel proinflammatory human skin-homing Vgamma9Vdelta2 $\mathrm{T}$ cell subset with a potential role in psoriasis. J Immunol (2011) 187:2783-93. doi: 10.4049/jimmunol.1100804

102. Rhodes KA, Andrew EM, Newton DJ, Tramonti D, Carding SR. A subset of IL-10-producing gammadelta $\mathrm{T}$ cells protect the liver from Listeria-elicited, CD8(+) T cell-mediated injury. Eur J Immunol (2008) 38:2274-83. doi: 10.1002/eji.200838354

103. Patil RS, Bhat SA, Dar AA, Chiplunkar SV. The Jekyll and Hyde story of IL17-Producing gammadeltaT Cells. Front Immunol (2015) 6:37. doi: 10.3389/fimmu.2015.00037 
104. Palomino-Segura M, Latino I, Farsakoglu Y, Gonzalez SF. Early production of IL-17A by gammadelta $\mathrm{T}$ cells in the trachea promotes viral clearance during influenza infection in mice. Eur J Immunol (2020) 50:97-109. doi: 10.1002/eji.201948157

105. DiTirro J, Rhoades ER, Roberts AD, Burke JM, Mukasa A, Cooper AM, et al. Disruption of the cellular inflammatory response to Listeria monocytogenes infection in mice with disruptions in targeted genes. Infect Immun (1998) 66:2284-9. doi: 10.1128/IAI.66.5.2284-2289.1998

106. Skeen MJ, Freeman MM, Ziegler HK. Changes in peritoneal myeloid populations and their proinflammatory cytokine expression during infection with Listeria monocytogenes are altered in the absence of gamma/delta T cells. J Leukoc Biol (2004) 76:104-15. doi: 10.1189/jlb.1103574

107. Tramonti D, Andrew EM, Rhodes K, Newton DJ, Carding SR. Evidence for the opposing roles of different gamma delta $\mathrm{T}$ cell subsets in macrophage homeostasis. Eur J Immunol (2006) 36:1729-38. doi: 10.1002/eji.200635959

108. Brandes M, Willimann K, Moser B. Professional antigen-presentation function by human gammadelta T Cells. Science (2005) 309:264-8. doi: $10.1126 /$ science. 1110267

109. D'Asaro M, La Mendola C, Di Liberto D, Orlando V, Todaro M, Spina M, et al. $\mathrm{V}$ gamma $9 \mathrm{~V}$ delta $2 \mathrm{~T}$ lymphocytes efficiently recognize and kill zoledronate-sensitized, imatinib-sensitive, and imatinib-resistant chronic myelogenous leukemia cells. J Immunol (2010) 184:3260-8. doi: 10.4049/ jimmunol.0903454

110. Li W, Kubo S, Okuda A, Yamamoto H, Ueda H, Tanaka T, et al. Effect of IL-18 on expansion of gammadelta T cells stimulated by zoledronate and IL-2. J Immunother (2010) 33:287-96. doi: 10.1097/CII.0b013e3181c80ffa

111. Bansal RR, Mackay CR, Moser B, Eberl M. IL-21 enhances the potential of human gammadelta T cells to provide B-cell help. Eur J Immunol (2012) 42:110-9. doi: 10.1002/eji.201142017

112. Wu K, Zhao H, Xiu Y, Li Z, Zhao J, Xie S, et al. IL-21-mediated expansion of Vgamma9Vdelta2 $\mathrm{T}$ cells is limited by the Tim-3 pathway. Int Immunopharmacol (2019) 69:136-42. doi: 10.1016/j.intimp.2019.01.027

113. Caccamo N, Battistini L, Bonneville M, Poccia F, Fournie JJ, Meraviglia S, et al. CXCR5 identifies a subset of Vgamma9Vdelta2 $\mathrm{T}$ cells which secrete IL4 and IL-10 and help B cells for antibody production. J Immunol (2006) 177:5290-5. doi: 10.4049/jimmunol.177.8.5290

114. Hawkes JE, Yan BY, Chan TC, Krueger JG. Discovery of the IL-23/IL-17 Signaling Pathway and the Treatment of Psoriasis. J Immunol (2018) 201:1605-13. doi: 10.4049/jimmunol.1800013

115. Ogawa E, Sato Y, Minagawa A, Okuyama R. Pathogenesis of psoriasis and development of treatment. J Dermatol (2018) 45:264-72. doi: 10.1111/13468138.14139

116. Rizzo HL, Kagami S, Phillips KG, Kurtz SE, Jacques SL, Blauvelt A. IL-23mediated psoriasis-like epidermal hyperplasia is dependent on IL-17A. J Immunol (2011) 186:1495-502. doi: 10.4049/jimmunol.1001001

117. Tortola L, Rosenwald E, Abel B, Blumberg H, Schafer M, Coyle AJ, et al. Psoriasiform dermatitis is driven by IL-36-mediated DC-keratinocyte crosstalk. J Clin Invest (2012) 122:3965-76. doi: 10.1172/JCI63451

118. Brembilla NC, Senra L, Boehncke WH. The IL-17 Family of Cytokines in Psoriasis: IL-17A and Beyond. Front Immunol (2018) 9:1682. doi: 10.3389/ fimmu.2018.01682

119. Singh TP, Zhang HH, Hwang ST, Farber JM. IL-23- and ImiquimodInduced Models of Experimental Psoriasis in Mice. Curr Protoc Immunol (2019) 125:e71. doi: 10.1002/cpim.71

120. Pantelyushin S, Haak S, Ingold B, Kulig P, Heppner FL, Navarini AA, et al. Rorgammat+ innate lymphocytes and gammadelta $\mathrm{T}$ cells initiate psoriasiform plaque formation in mice. J Clin Invest (2012) 122:2252-6. doi: 10.1172/JCI61862

121. Cai Y, Shen X, Ding C, Qi C, Li K, Li X, et al. Pivotal role of dermal IL-17producing gammadelta $\mathrm{T}$ cells in skin inflammation. Immunity (2011) 35:596-610. doi: 10.1016/j.immuni.2011.08.001

122. Cai Y, Xue F, Qin H, Chen X, Liu N, Fleming C, et al. Differential Roles of the mTOR-STAT3 Signaling in Dermal gammadelta T Cell Effector Function in Skin Inflammation. Cell Rep (2019) 27:3034-48.e5. doi: 10.1016/j.celrep.2019.05.019

123. Cai Y, Xue F, Fleming C, Yang J, Ding C, Ma Y, et al. Differential developmental requirement and peripheral regulation for dermal Vgamma4 and Vgamma6T17 cells in health and inflammation. Nat Commun (2014) 5:3986. doi: 10.1038/ncomms4986
124. Katayama H. Development of psoriasis by continuous neutrophil infiltration into the epidermis. Exp Dermatol (2018) 27:1084-91. doi: 10.1111/exd.13746

125. Mabuchi T, Takekoshi T, Hwang ST. Epidermal CCR6+ gammadelta T cells are major producers of IL-22 and IL-17 in a murine model of psoriasiform dermatitis. J Immunol (2011) 187:5026-31. doi: 10.4049/jimmunol.1101817

126. Mabuchi T, Singh TP, Takekoshi T, Jia GF, Wu X, Kao MC, et al. CCR6 is required for epidermal trafficking of gammadelta- $\mathrm{T}$ cells in an IL-23-induced model of psoriasiform dermatitis. J Invest Dermatol (2013) 133:164-71. doi: 10.1038/jid.2012.260

127. Getschman AE, Imai Y, Larsen O, Peterson FC, Wu X, Rosenkilde MM, et al. Protein engineering of the chemokine CCL20 prevents psoriasiform dermatitis in an IL-23-dependent murine model. Proc Natl Acad Sci U S A (2017) 114:12460-5. doi: 10.1073/pnas.1704958114

128. Hedrick MN, Lonsdorf AS, Hwang ST, Farber JM. CCR6 as a possible therapeutic target in psoriasis. Expert Opin Ther Targets (2010) 14:911-22. doi: $10.1517 / 14728222.2010 .504716$

129. Furue K, Ito T, Tsuji G, Nakahara T, Furue M. The CCL20 and CCR6 axis in psoriasis. Scand J Immunol (2020) 91:e12846. doi: 10.1111/sji.12846

130. Gisondi P, Geat D, Pizzolato M, Girolomoni G. State of the art and pharmacological pipeline of biologics for chronic plaque psoriasis. Curr Opin Pharmacol (2019) 46:90-9. doi: 10.1016/j.coph.2019.05.007

131. Sbidian E, Chaimani A, Afach S, Doney L, Dressler C, Hua C, et al. Systemic pharmacological treatments for chronic plaque psoriasis: a network metaanalysis. Cochrane Database Syst Rev (2020) 1:CD011535. doi: 10.1002/ 14651858.CD011535.pub3

132. Conrad C, Gilliet M. Psoriasis: from Pathogenesis to Targeted Therapies. Clin Rev Allergy Immunol (2018) 54:102-13. doi: 10.1007/s12016-018-8668-1

133. Mrowietz U, Barker J, Boehncke WH, Iversen L, Kirby B, Naldi L, et al. Clinical use of dimethyl fumarate in moderate-to-severe plaque-type psoriasis: a European expert consensus. J Eur Acad Dermatol Venereol (2018) 32(Suppl 3):3-14. doi: 10.1111/jdv.15218

134. Dieli F, Sireci G, Di Sano C, Romano A, Titone L, Di Carlo P, et al. Ligandspecific alphabeta and gammadelta $\mathrm{T}$ cell responses in childhood tuberculosis. J Infect Dis (2000) 181:294-301. doi: 10.1086/315180

135. Pitard V, Roumanes D, Lafarge X, Couzi L, Garrigue I, Lafon ME, et al. Longterm expansion of effector/memory Vdelta2-gammadelta $\mathrm{T}$ cells is a specific blood signature of CMV infection. Blood (2008) 112:1317-24. doi: 10.1182/ blood-2008-01-136713

136. Sheridan BS, Romagnoli PA, Pham QM, Fu HH, Alonzo F,3, Schubert WD, et al. gammadelta $\mathrm{T}$ cells exhibit multifunctional and protective memory in intestinal tissues. Immunity (2013) 39:184-95. doi: 10.1016/j.immuni.2013.06.015

137. Khairallah C, Chu TH, Sheridan BS. Tissue Adaptations of Memory and Tissue-Resident Gamma Delta T Cells. Front Immunol (2018) 9:2636. doi: 10.3389/fimmu.2018.02636

138. Zhu R, Cai X, Zhou C, Li Y, Zhang X, Li Y, et al. Dermal Vgamma4(+)T cells enhance the IMQ-induced psoriasis-like skin inflammatidon in rechallenged mice. Am J Transl Res (2017) 9:5347-60.

139. Hartwig T, Pantelyushin S, Croxford AL, Kulig P, Becher B. Dermal IL-17producing gammadelta $\mathrm{T}$ cells establish long-lived memory in the skin. Eur J Immunol (2015) 45:3022-33. doi: 10.1002/eji.201545883

140. Holtmeier W, Pfander M, Hennemann A, Zollner TM, Kaufmann R, Caspary WF. The TCR-delta repertoire in normal human skin is restricted and distinct from the TCR-delta repertoire in the peripheral blood. J Invest Dermatol (2001) 116:275-80. doi: 10.1046/j.1523-1747.2001.01250.x

141. de Boer OJ, Verhagen CE, Visser A, Bos JD, Das PK. Cellular interactions and adhesion molecules in psoriatic skin. Acta Derm Venereol Suppl (Stockh) (1994) $186: 15-8$.

142. Harden JL, Hamm D, Gulati N, Lowes MA, Krueger JG. Deep Sequencing of the T-cell Receptor Repertoire Demonstrates Polyclonal T-cell Infiltrates in Psoriasis. F1000Res (2015) 4:460. doi: 10.12688/f1000research.6756.1

143. Lalor SJ, McLoughlin RM. Memory gammadelta T Cells-Newly Appreciated Protagonists in Infection and Immunity. Trends Immunol (2016) 37:690702. doi: $10.1016 /$ j.it.2016.07.006

144. Liu JT, Xue F, Li X, Shi RF, Zheng J. Preliminary Study of T Cell Receptor V $\gamma$ Gene Usage of $\gamma \delta \mathrm{T}$ Cells in Psoriatic Skin Lesions. Chin J Dermatovenereol (2012) 26:571-4.

145. Ness-Schwickerath KJ, Jin C, Morita CT. Cytokine requirements for the differentiation and expansion of IL-17A- and IL-22-producing human 
Vgamma2Vdelta2 T cells. J Immunol (2010) 184:7268-80. doi: 10.4049/ jimmunol.1000600

146. Ruan H, Dong LQ. Adiponectin signaling and function in insulin target tissues. J Mol Cell Biol (2016) 8:101-9. doi: 10.1093/jmcb/mjw014

147. Shibata S, Tada Y, Hau CS, Mitsui A, Kamata M, Asano Y, et al. Adiponectin regulates psoriasiform skin inflammation by suppressing IL-17 production from gammadelta-T cells. Nat Commun (2015) 6:7687. doi: 10.1038/ncomms8687

148. Bekiaris V, Sedy JR, Macauley MG, Rhode-Kurnow A, Ware CF. The inhibitory receptor BTLA controls gammadelta $\mathrm{T}$ cell homeostasis and inflammatory responses. Immunity (2013) 39:1082-94. doi: 10.1016/ j.immuni.2013.10.017

149. Youssef RM, El-Ramly AZ, Hussien MF, Shoukry NM, Amr K. Expression of $\mathrm{B}$ and $\mathrm{T}$ lymphocyte attenuator, retinoid-related orphan receptor gammaisoform-t and interleukin 7 in psoriasis vulgaris. Australas J Dermatol (2019) 60:e132-7. doi: 10.1111/ajd.12965

150. Hurchla MA, Sedy JR, Gavrieli M, Drake CG, Murphy TL, Murphy KM, et al. $\mathrm{B}$ and $\mathrm{T}$ lymphocyte attenuator exhibits structural and expression polymorphisms and is highly Induced in anergic CD4+ T cells. J Immunol (2005) 174:3377-85. doi: 10.4049/jimmunol.174.6.3377

151. Cochez PM, Michiels C, Hendrickx E, Dauguet N, Warnier G, Renauld JC, et al. Ccr6 Is Dispensable for the Development of Skin Lesions Induced by Imiquimod despite its Effect on Epidermal Homing of IL-22-Producing Cells. J Invest Dermatol (2017) 137:1094-103. doi: 10.1016/j.jid.2016.12.023

152. Maeda Y, Seki N, Kataoka H, Takemoto K, Utsumi H, Fukunari A, et al. IL17-Producing Vgamma4+ gammadelta T Cells Require Sphingosine 1Phosphate Receptor 1 for Their Egress from the Lymph Nodes under Homeostatic and Inflammatory Conditions. J Immunol (2015) 195:1408-16. doi: $10.4049 /$ jimmunol.1500599
153. Xie XJ, Di TT, Wang Y, Wang MX, Meng YJ, Lin Y, et al. Indirubin ameliorates imiquimod-induced psoriasis-like skin lesions in mice by inhibiting inflammatory responses mediated by IL-17A-producing gammadelta T cells. Mol Immunol (2018) 101:386-95. doi: 10.1016/ j.molimm.2018.07.011

154. Byamba D, Kim DY, Kim DS, Kim TG, Jee H, Kim SH, et al. Skinpenetrating methotrexate alleviates imiquimod-induced psoriasiform dermatitis via decreasing IL-17-producing gamma delta T cells. Exp Dermatol (2014) 23:492-6. doi: 10.1111/exd.12448

155. Buck MD, Sowell RT, Kaech SM, Pearce EL. Metabolic Instruction of Immunity. Cell (2017) 169:570-86. doi: 10.1016/j.cell.2017.04.004

156. Shehata HM, Murphy AJ, Lee MKS, Gardiner CM, Crowe SM, Sanjabi S, et al. Sugar or Fat?-Metabolic Requirements for Immunity to Viral Infections. Front Immunol (2017) 8:1311. doi: 10.3389/fimmu.2017.01311

157. Dimeloe S, Burgener AV, Grahlert J, Hess C. T-cell metabolism governing activation, proliferation and differentiation; a modular view. Immunology (2017) 150:35-44. doi: 10.1111/imm.12655

Conflict of Interest: The authors declare that the research was conducted in the absence of any commercial or financial relationships that could be construed as a potential conflict of interest.

Copyright $\odot 2021$ Qi, Wang, Li and Zhao. This is an open-access article distributed under the terms of the Creative Commons Attribution License (CC BY). The use, distribution or reproduction in other forums is permitted, provided the original author(s) and the copyright owner(s) are credited and that the original publication in this journal is cited, in accordance with accepted academic practice. No use, distribution or reproduction is permitted which does not comply with these terms. 